the detailed features of the noise in the frequencyrange $15 \mathrm{kc} . / \mathrm{s} .-30 \mathrm{Mc} . / \mathrm{s}$. with tho view of elucidating the mechanism whereby individual lightning flashes give rise to noise at different frequencies.

Observations of the phase and amplitude characteristics of very low-frequency waves $(10-20 \mathrm{kc} / \mathrm{s}$. reflected from the ionosphere are also described in "Radio Research 1957". The experimental work, which bears directly on the application of such waves for navigational aids over long distances, is being supplemented by theoretical work on the propagation of very low-frequency waves.

In addition to the work on radio propagation over a wide frequency-range, the Department is engaged on the development of radio-frequency power measuring standards, and research into semi-conductors and magnetic and dielectric materials. Work on germanium has been superseded by that on silicon filaments and commercial transistors, with particular reference to performance at very high radio-frequencies. The magnetic properties of a wide range of ferrites and other metal oxides and their applications to microwave measurements are being investigated.

Some of the work described in the report is undertaken, under contract with the Department, at various universities. A list of papers published during 1957 is given as an appendix. GeOFFrey M. Brow

\title{
ECOLOGY OF SOIL FUNGI
}

\begin{abstract}
HE growth, activities and interrelationships of fungi in soil provided the basis for a symposium on "The Ecology of Soil Fungi" held at the University of Liverpool during August 19-2l. The meeting, attended by ninety scientists from thirteen countries, was divided into six sessions, which were presided over, respectively, by Prof. N. A. Burges (University of Liverpool), Dr. P. W. Brian (Imperial Chemical Industries, Welwyn), Dr. J. Harley (University of Oxford), Prof. J. Guillemat (École National d'Agronomique, Grignon), Prof. J. Ziemiecka (Institut Uprawy, Pulawy, Poland) and Dr. H. Katznelson (Canadian Department of Agriculture, Ottawa). Each session included a review of one aspect of the subject and four or five shorter papers : most of the twenty-eight papers presented were circulated before the symposium and this undoubtedly contributed greatly to the very lively discussions.
\end{abstract}

Review papers by Dr. J. H. Warcup (Waite Agricultura] Institute, Adelaide, read by Dr. Parkinson and J. S. Waid (Fisons, Levington) dealt, respectively, with the isolation and estimation of activity of fungi in soil and the effect of environmental conditions on fungal growth in soil. Synecological investigations which were afterwards discussed included: the fungi associated with pine litter and couch grass debris (Dr. D. Parkinson and B. Kendrick, University of Liverpool); the distribution of Chytrids in lake muds and soil (Dr. L. G. Willoughby, Fresh Water Biological Association, Ambleside); the microflora of sandy soils in the Sahara (Dr. J. Nicot, Natural History Museum, Paris); the fungal flora of tidal mud flats before and during colonization by Salicornia stricta (Dr. G. J. F. Pugh, University of Nottingham); the growth of fungi in forest and grassland soils (Dr. R. H. Thormton, Soil Bureau, Wellington, New Zealand, read by Dr. Parkinson); and the rhizosphere flora of Abies of different ages (Dr. R. Moreau, Ecole Nationale de Médecine et de Pharmacie, Besançon). During the course of these papers and the discussions, the need for a greater knowledge of the origin of fungal isolates was emphasized. The use of the soil dilution plate count method, a subject of some considerable debate, was ably defended by Prof. J. Montegut (École National de Horticulture, Versailles), and an account of the use of this method in studies of the effects of nitrogen, phosphorus and potassium on soil fungi was submitted by Profs. J. Guillemat and J. Montegut. Dr. E. H. Garrard
(Ontario Agricultural College) surveyed the detailed work on Streptomyces scabies at Guelph. Directobservation studies of Verticillium albo-atrum in soil and tomato roots were described by Dr. G. W. F. Sewell (East Malling Research Station), and Dr. H. Tribe (University of Cambridge; read by Dr. S. Hepple, National Institute of Agricultural Botany, Cambridge) discussed his observational work on the decomposition of buried cellulose film.

A review by Dr. Brian of the antagonistic and competitive mechanisms limiting survival and activity of fungi in soil was followed by an account of antagonism as the background in which fungi live (Dr. D. Park, University of Manchester), and a description by Dr. R. Barton (University of Manchester) of investigations of substrate colonization by Pythium mamillatum under different conditions. Drs. A. G. Winter, F. Schonbeck and H. Peuss (Botanische Abteilung Madans, Köln Merhiem) discussed biotic factors, with reference to 'hyphospheres' and mycorrhizæ, affecting the development of soil fungi. Soil fungistasis, which Dr. Brian also included in his survey, was the subject of a paper by Dr. C. G. Dobbs, who reviewed some methods of study developed at the University College of North Wales, Bangor. Drs. Dobbs and J. Bywater (Bangor) described a seasonal variation in fungistasis in certain soils, and Dr. R. M. Jackson (Rothamsted Experimental Station) discussed the effect of living roots on the germination of fungal spores in soil.

Prof. Burges, in his paper "Dynamic Equilibrium of Soil Populations", discussed the effects on the soil micropopulation of seasonal fluctuation in depositions of organic matter. The uses of radiocarbon in studies on cellulose and lignin breakdown were described by Dr. J. Mayandon and Prof. P. Simonart (University of Louvain), while problems associated with the isolation of humic acid and its utilization as a nutrient by fungi were the subjects of a paper by Prof. Burges and Miss P. M. Latter. Certain aspects of fungal physiology in relation to soil studies were reviewed by Dr. Harley, whose paper was followed by accounts of the use of physiological methods, relating to oxidative metabolism, in mycological studies (Dr. D. Boulter and H. M. Hurst, University of Liverpool) and a demonstration by Dr. M. E. K. Henderson (Macaulay Institute, Aberdeen) that a number of fungi are able to decompose molecules related to lignin. Prof. C. G. C. Chesters (University of Nottingham) reviewed prob- 
lems associated with the decomposition of organic matter in soils and stressed that all the different organisms concermed should be considered.

Dr. Katznelson, in an evening lecture, surveyed the work of the Bacteriology Division of the Canadian Department of Agriculture on rhizosphere problems. The ecological events in the rhizosphere and the general health of the plant were discussed in the light of the results of these studies.

Demonstrations, which were available for inspection throughout the period of the symposium, included an exhibition of the use of tracer techniques with special reference to studies of fungal growth in soil (Dr. E. Grossbard, Grassland Research Station, Hurley), the screened immersion plate technique (Dr. Thornton), and examples of soil sections prepared by a resin impregnation method (Dr. S. Hepple and Prof. Burges). The other exhibits were concerned with mycorrhizal studies. Slides and figures illustrating internal and external mycelial phases of vesicular-arbuscular endophytes associated with grass roots were presented by Dr. T. H. Nicolson (University of Nottingham), and Dr. B. Mosse (East Malling Research Station) demonstrated a method of obtaining pure inocula of an Endogone sp. capable of causing vesicular-arbuscular mycorrhizal infections : typical infections produced in apple, strawberry and onion roots were shown. Dr. D. G. Downie (University of Aberdeen) demonstrated strains of Rhizoctonia solani, pathogenic to potato, wheat and cauliflower, which stimulated embryo development of Orchis purpurella, and Dr. I. Levisohn (Bedford College, London) showed the growth of mycorrhizal mycelia on sterilized litter.

It is a pleasure to record the generous hospitality of the University of Liverpool and the excellent organization of this most informative and enjoyable meeting. The organizers are preparing the full proceedings of the symposium for publication by the University of Liverpool Press.

$$
\text { G. J. F. PUGH }
$$

G. W. F. SEWELL

\section{PHYSICS OF ICE MOVEMENT}

\begin{abstract}
A SYMPOSIUM on the "Physics of Ice Movement" was held at Chamonix during September 16 24. It was organized by the International Association of Scientific Hydrology for its daughter Commission for Snow and Ice, and was attended by some eightyfive glaciologists from fifteen countries. The work of the symposium was greatly facilitated by the feat of the secretary of the Association, Prof. L. J. Tison, in publishing the forty-one papers submitted for the symposium in time for the opening session*. The president of the Commission, Prof. R. Finsterwalder (Munich), presided over the symposium, and Prof. A. Bauer, one of the vice-presidents, organized the details ; despite poor weather, he managed to arrange two whole-day excursions of great glaciological interest as well as twelve working sessions. It is, of course, impossible to summarize all the papers here, and I will only try to give some impression of the material presented in the wide range of relevant subjects discussed, which ranged from the deformation of single crystals of ice to the behaviour of the Antarctic ice sheet.

Prof. U. Nakaya (Sapporo, Japan) reported the results of some very beautiful tests performed on single crystals of ice of great perfection derived from an Alaskan glacier. Rectangular bars cut from these crystals in various orientations had been deformed by bending, and the resulting deformation studied by shadow photography, which reveals the glide planes, and by polarized light, to determine changes in crystal orientation. All the phenomena of gliding and low-angle boundaries observed in hexagonal metals are to be seen, and the geometry of the deformation, deduced by Nakaya, was shown by Dr. J. F. Nye (Bristol) in the symposium to have a close relation to the theory of deformation by continuous distributions of dislocations. The flow law for ice single crystals was discussed by Dr. T. R. Butkovich and Dr. J. K. Landauer (Snow, Ice and Permafrost Research Establishment, United States),

* Union Géodésique et Géophysique Internationale, Association Internationale d'Hydrologie Scientifique, Symposium de Chamonix 16-24 Sept., 1958. (Gentbrugge : Association Internationale d' Hydro-
\end{abstract}

who found that for single crystals, like polycrystalline aggregates, the relation between minimum strain rate and stress can be well represented by a power law for stresses around 1 bar. They used shear tests, and found that if the crystal is oriented for easy glide on the basal plane, the flow is considerably faster than for polycrystals, whereas if the specimen is oriented so that no glide on the basal plane is possible under the applied stress, then the minimum strain-rate is of the same magnitude as that of polycrystals. Butkovich and Landauer also reported results of tests on polycrystalline ice, and further tests of this kind were reported by Prof. S. S. Vyalov (U.S.S.R.) and by Dr. S. Steinemann (Neuchâtel, Switzerland). They all confirmed that a power law represents the data well over a range of strain rates from $10^{-8}$ to $10^{-5}$ sec.-1, but at the limits of this range there are signs that the law ceases to hold, in the sense that the power decreases for the low strain-rates and increases for the high ones. Steinemann also found that he could plot a similar power law for the final strain-rate to which the speci. men settles down (as opposed to the minimum rate). In this state the ice is recrystallizing during the creep, and it is of particular interest that he has results for both compression and shear tests so that the relations usually assumed to hold between the results of these two types of stressing system can be tested. $\mathrm{He}$ finds that the relations are not obeyed, and that the disagreement is particularly bad in the case of the final rate-a result which is perhaps not so surprising when it is realized that the recrystallization is producing quite different textures in the two cases. Since, however, it is this final rate which is probably most relevant to the rate of flow observed in glaciers, this may well mean that glacier theories made with the usual assumptions are subject to some error. Dr. J. W. Glen (Birmingham) in his paper discussed what possibilities there might be for a flow law without making the assumptions in question.

Experiments on glaciers which have bearing on the mechanical properties of ice were reported by several authors. Dr. B. L. Hansen and Dr. Landauer (Snow, 